\title{
Effect of Integrated Physical Activity Training on Social Phobia in girls residing in a children's home
}

\author{
Anagha Kulkarni \\ ${ }^{1}$ Director of Physical Education and Sports, L.S. Raheja College of Arts and Commerce, Mumbai \\ Corresponding author: Dr.Anagha Kulkarni \\ Email - anaghak86@gmail.com
}

\begin{abstract}
The purpose of the study was to determine the effect of integrated physical activity training on social phobia. In this experimental research study, the subjects were 51 girls (age 13 to 16 years) of children's homes of Greater Mumbai. The design of the study was Non-equivalent Control Group Design. The dependent variable was social phobia and the psychological test administered was Social Phobia Scale (SPS). The independent variable (treatment) was Integrated Physical Activity Training for the period of 8 weeks, 5 days a week and 60 minutes morning session which comprised of yoga, physical exercise and team games. The comparison of data (pre test - post test) of control group and experimental group was analyzed with the help of one way analysis of covariance Ancova. The result added new information that the level of social phobia has been reduced due to the treatment of Integrated Physical Activity Training among the adolescent girls of children's home.
\end{abstract}

Keywords: Children's home, Integrated, Physical activity and Social phobia.

(Paper received $-4^{\text {th }}$ January 2018 , Peer review completed $-12^{\text {th }}$ January 2018)

(Accepted $-14^{\text {th }}$ January 2018)

\section{INTRODUCTION}

Health and Fitness requires a multi-dimensional, approach that fits into one's lifestyle as naturally and effortlessly as possible. If the focus of a health program is only on physical goals, without taking into account the physiological and psychological aspects of exercise and healthy living, the results will likely be short-lived and the exercise itself unsatisfying. Holistic Fitness Training strongly emphasizes on creating exercise programs that identify the goals and the obstacles - physical, physiological, and emotional - that will affect one's commitment and progress. The regular physical exercises enable the individual to stay physically fit and to sustain the average individual in his daily activities. People approach fitness by various ways and means to keep themselves healthy and fit but their efforts towards fitness is always partly accomplished by way of adopting physical exercise, aerobics or yoga practices and sometimes recreational sports and games.

Social Phobia is defined by DSM-IV-TR as an anxiety disorder characterized by a strong and persistent fear of social or performance situations in which the individual might feel embarrassment or humiliation. Generalized social phobia refers to a fear of most social interactions combined with fear of most performance situations, such as speaking in public or eating in a restaurant. Social phobia, which is also known as Social Anxiety Disorder, is a serious mental health problem in the United States. In any given year, social phobia affects $3.7 \%$ of the American population between the ages of 18 and 54 , or about 5.3 million people. It is the third most common psychiatric condition after depression and alcoholism. In some 
young people, the disorder grows out of a long-term history of shyness or social inhibition. In others, social phobia becomes apparent following a move to a new school or similar developmental challenge. The onset of social phobia almost always occurs in childhood or the mid teens; onset after age 25 is unusual. The disorder is often a lifelong problem, although its severity may diminish in adult life. Adults and adolescents with social phobia, as well as many children with the disorder, have sufficient insight to recognize that their fears are excessive or unwarranted. This factor often adds to their distress and feelings of inferiority. Social phobia is of major concern to society as a whole.

The objectives sought by the researcher is as follows -

(i) To find out the effect of Integrated Physical Training on Social Phobia of Children's Home girls.

\section{The Null Hypothesis sought by the researcher is as follows -}

There is no significance difference in adjusted mean scores of Social Phobia of Children's Home Girls of Integrated Physical Activity Training Group and Non-Integrated Physical Activity Training Group by considering pre-social phobia as covariate.

\section{METHODOLOGY}

\section{Selection of Sample}

A sample of Fifty One $(n=51)$ girls age ranging from 13-16 years were randomly selected and identified as subjects. The Experimental group was comprised of 26 girls of Children's Home, Dongri and the Control group was comprised of 25 girls of Maharashtra State Women's Council's (MSWC) Asha Sadan (Balgruha - Adhargruh), Jail Road, Umerkhadi, Dongri. Both the organizations are in the same vicinity of Mumbai and they also cater to the girls suffering from the similar socio-economic crisis and social problems.

\section{Research Design}

The design of the study was 'Non-equivalent Experiment Group Design'. The design of the experiment had been planned in three phase's viz., Phase - I: Pre-test, Phase - II: Training or Treatment, and Phase - III: Post-test. The selected subjects were divided into two groups; one Integrated Physical Training Group (Experimental group) and one Non-Integrated Physical Training Group (Control group) Integrated Physical Training Group had 26 subjects while, Non-Integrated Physical Training Group had 25 subjects. The Integrated Physical Training Group had been given treatment i.e., Integrated Physical Training for the period of 8 weeks; 5 days a week and 60 minutes in morning session. Non-Integrated Physical Training Group did not receive any training but, involved in their routine work. The Pre test and Post test were conducted administering standardized psychological test i.e.; Social Phobia Scale (SPS).

\section{Selected Variables}

Dependent Variables: Social Phobia(Psychological Variable)

Independent Variables: Integrated Physical Activity Training (Treatment)

Yoga: (i) Yogic Exercise / Yogic Posture / Yogasana, (ii) Kriyas, (iii) Pranayama and (iv) Meditation Physical Exercise: (i) Strength Exercise, (ii) Endurance Exercise and (iii) Flexibility Exercise

Team Games: (i) Relays and (ii) Minor Games

\section{Tools / Instruments}

The subjects in both the groups, the Integrated Physical Activity Training Group (Experimental Group) and one Non-Integrated Physical Activity Training Group (Control group) were assessed with the help of selected standardized test Social Phobia Scale (SPS) before (Pre-test) and after (Post-test) the treatment. The Social Phobia Scale by Sisodia and Sharma was used in the assessment of the subjects in the study.

\section{Statistical Analysis}

Since, this experimental study comprised of two groups - Integrated Physical Activity Training Group (Experimental Group) and Non- Integrated Physical Activity Training Group (Control Group). The researcher decided to compare adjusted mean scores of Social Phobia in order to find out the effect of given treatment on Social Phobia of Children's Home girls. One Way Analysis of Covariance ANCOVA was appropriately used for the data analysis with the help of SPSS (Statistical Package for Social Sciences). 


\section{RESULTS AND DISCUSSION}

From Table 1 it can be seen that the adjusted F-value is 64.15 which is significant at 0.01 level with $\mathrm{df}=$ 1/48 when Pre Social Phobia was taken as covariant. It shows that adjusted mean scores of Social Phobia of Integrated Physical Activity Training Group (Experimental Group) and Non-Integrated Physical Activity Training Group (Control Group) differ significantly when Pre Social Phobia as a Covariate. Thus, the Null Hypothesis that - " $\mathrm{H}_{01}$ : There is no significant difference in adjusted mean scores of Social Phobia of Children's Home Girls of Integrated Physical Activity Training Group and Non-Integrated Physical Activity Training Group by taking Pre Social Phobia as a Covariate" is rejected.

Table 1 - ANCOVA table

\begin{tabular}{|l|l|l|l|l|l|}
\hline Source of variance & df & SSy.x & MSSy.x & Fy.x & Remark \\
\hline Group & 1 & 43.99 & 43.99 & & \\
\cline { 1 - 4 } Error & 48 & 32.91 & 0.69 & \multirow{2}{*}{64.15} & \multirow{2}{*}{$p<0.01$} \\
\cline { 1 - 4 } Total & 51 & & & & \\
\hline
\end{tabular}

Further the adjusted mean score of Social Phobia of Integrated Physical Activity Training Group is 74.21 which is significantly higher than that of Non-Integrated Physical Activity Training Group where adjusted mean score of Social Phobia is 76.15. It may, therefore, be said that Integrated Physical Activity Training Group was found to be effective in reducing the level of Social Phobia of Children's Home Girls than that of Non-IntegratedPhysical Activity Training Group where Pre Social Phobia was taken as covariate. The above result is also presented graphically in the Fig. 1.

Figure 1 - Treatment wise Comparison of Adjusted Mean Scores of Social Phobia

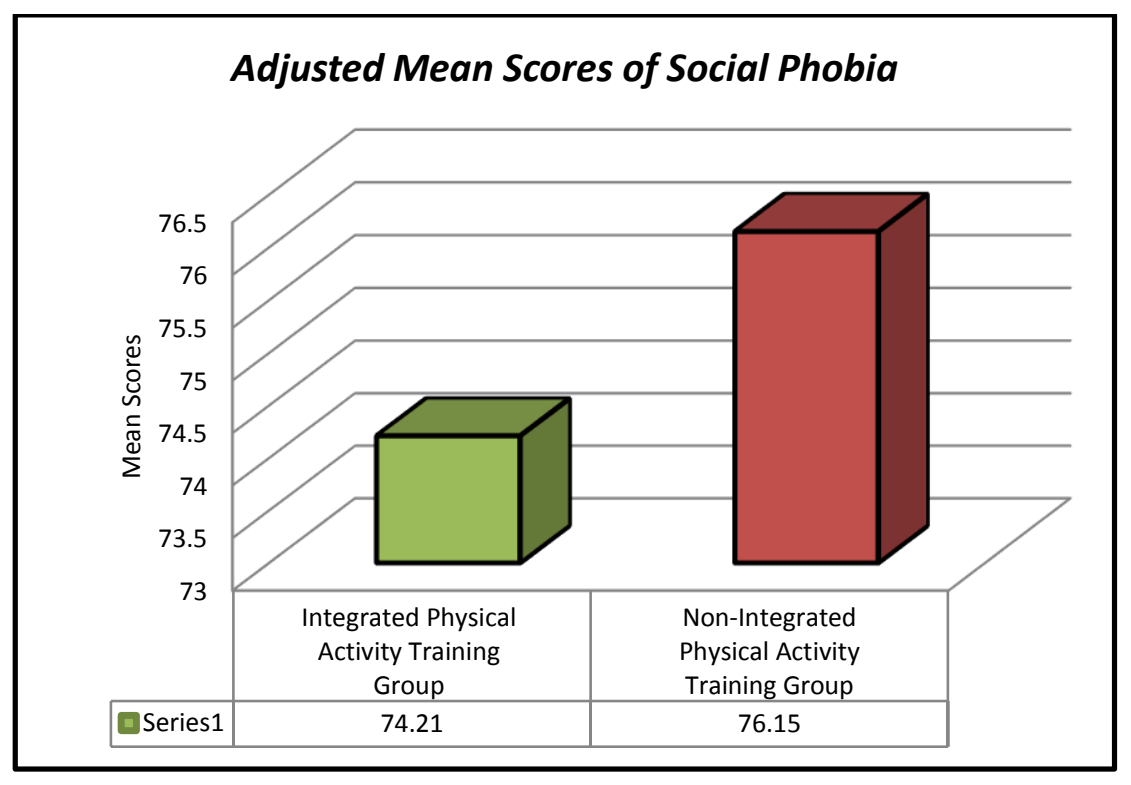

\section{CONCLUSION}

The Social Phobia has been reduced significantly as a result of treatment. i.e., Integrated Physical Activity Training given to the Children's Home Girls of aged 13 to 16 years of Greater Mumbai. Thus, the given treatment is helpful in tackling social anxiety disorder namely Social Phobia. 
The study would inspire Physical Education Teachers, Coaches and Social Workers for the further study. The study would inspire researchers to conduct similar study on the Children's Home Boys and inmates of Observation Home / Remand Home. The study would inspire researchers to conduct similar studies on different institution and NGOs providing shelter and protection and care facility. The study will encourage administrators, child-woman welfare officers and other government officials and NGOs to conduct or organize Physical Training for the welfare of children and women.

\section{RECOMMENDED READING}

1. Norton PJ, Burns JA, Hope DA, Bauer BK. Generalization of social anxiety to sporting and athletic situations: gender, sports involvement, and parental pressure. Depress Anxiety 2000;12(4):193-202.

2. Spence SH, Donovan C, Brechman-Toussaint M. The treatment of childhood social phobia: The effectiveness of a social skills training-based, cognitive-behavioural intervention, with and without parental involvement. J Child Psychol Psychiatry 2000;41(6):713-26.

3. Ströhle A. Physical activity, exercise, depression and anxiety disorders. J Neural Transm 2009;116(6):777-88.

4. Paluska SA, Schwenk TL. Physical activity and mental health. Sports Med 2000;29(3):167-80.

5. Goldin PR, Manber T, Hakimi S, Canli T, Gross JJ. Neural bases of social anxiety disorder: emotional reactivity and cognitive regulation during social and physical threat. Arch Gen Psychiatry 2009;66(2):170-80.

6. Bailey R. Physical education and sport in schools: A review of benefits and outcomes. J School Health 2006;76(8):397-401.

7. Powers S. Exercise physiology: Theory and application to fitness and performance. McGraw-Hill Higher Education; 2014.

8. Gallahue DL, Donnelly FC. Developmental physical education for all children. Human Kinetics; 2007.

9. Heimberg RG, editor. Social phobia: Diagnosis, assessment, and treatment. Guilford Press; 1995.

10. Marshall JR, Lipsett S. Social phobia: From shyness to stage fright. Basic Books; 1994.

11. Wiederhold BK, Wiederhold MD. Virtual reality therapy for anxiety disorders: Advances in evaluation and treatment. American Psychological Association; 2005.

12. Sisodia DS, Sharma D. The Social Phobia Scale Manual - SPS SDSD. National Psychological Corporation : Agra ; 2010.

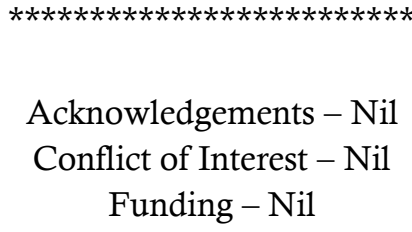

Funding - Nil 